\title{
費用関数法を用いる観測値と基礎方程式からの流れ場推定
}

\author{
塩田 卓 ${ }^{\circ}$ (大阪大学), 加賀 昭和 (大阪大学) \\ 近藤 明 (大阪大学), 井上 義雄 (大阪大学) \\ 山口 克人 (大阪大学)
}

\section{Estimation of Flow Field from Measured Data and Physical Equations using Cost Function Method}

Takashi SHIOTA, Akikazu KAGA, Akira KONDO, Yoshio INOUE and Katuhito YAMAGUCHI

\begin{abstract}
In recent years, various methods which attempt to reduce measurement errors and supplement data to data omission points by applying governing equations have been proposed. In this paper, we classify these methods according to the types of observations and equations used.

Subsequently, we propose GCFM(Generalized Cost Function Method) which reflects the observation data of velocity, temperature and mass concentration to the mutual estimation of each field by using the cost function defined by the summation of the residuals of governing equations and data corrections.

Finally we execute a numerical experiment for 2-dimentional steady non-isothermal flow field which contains pollutant emission sources to verify the effectiveness of GCFM, and we can confirm that our method is effective in the grasping of the flow fields.
\end{abstract}

Key Words: Cost function method, Flow estimation, PIV

\section{1.はじめに}

室全体など大空間の空気環境の構成要素である温度, 濃 度, 污染物質濃度の測定には, 測定系および人為的要因によ る誤差や, 特に速度計測に PIV を用いた場合においては久 測か存在するために, 定量的に精度よく把握することは一般 に困難である.

これに対し, 観測値の誤差の修正や欠測の復元に流れ場の 支配方程式を援用する試みがいくつかなされている. そこで 本報では, 従来流れ場の観測值推定を目的として提案されて いる手法の分類を行い, 各手法がどのような情報を用いて流 れ場を推定しようとしているかを明らかにする.

次に, 速度場以外に得られる観測値の情報を相互に反 映させる項を費用関数に取り入れた，一般化費用関数法GCFM(Generalized Cost Function Method) を定義し, 他 の手法との関係や, GCFM により速度場, 温度場, 濃度場 の情報を相互の場の推定に積極的に反映させた場合の効果を， 熱源および污染源を持つ二次元定常場の室内を対象とした数 值実験により検証する.

\section{2. 従来手法の分類}

ここでは,これまで提案されている流れ場の推定手法を, 対応する費用関数により分類する.

\section{1 費用関数法}

費用関数法を用いて観測値と基礎方程式から状態量を推定 する手法を一般化すると，以下のように表せる.
基礎方程式,

$$
f_{k}\left(\xi_{i}, \eta_{j}\right)=0
$$

ただし，

$\xi_{i}:$ 独立変数

$$
i=1,2,3 \text { (空間座標) }, \quad i=4 \text { (時間) }
$$

$\eta_{j} \quad$ : 従属変数

$j=1,2,3($ 速度成分 $u, v, w), j=4($ 圧力 $P$ )，

$j=5($ 温度 $\theta), \quad j=6($ 濃度 $c)$

$f_{k} \quad$ : 基礎方程式

$k=1,2,3$ ( $N S$ 方程式の $x, y, z$ 成分),

$k=4$ (連続式),$k=5$ (温度方程式),

$k=6($ 濃度方程式 $)$

について，残差の二乗および観測値の修正量の二乗の和を費 用関数 $C F$ とおくと,

$$
C F=\int\left\{\sum_{k} f_{k}^{2}\left(\xi_{i}, \eta_{j}\right)+\sum_{j}\left(\eta_{j}-\eta_{j, o b s}\right)^{2}\right\} d \xi
$$

と表される.ここで, $\int d \xi$ は対象領域全体にわたる全ての $\xi$ に関する積分を表している. 式 (2) を最小化する一手法亡 して,ここでは $\eta_{j}$ で偏微分して 0 とおいた式,

$$
\int\left\{\sum_{k} f_{k} \frac{\partial f_{k}}{\partial \eta_{j}}+\left(\eta_{j}-\eta_{j, o b s}\right)\right\} d \xi=0
$$

を解いて $\eta_{j}$ を求める方法を考える. なおここでは簡単のた め費用関数の各項の重みの表記は省略した. 
塩田 卓, 加賀昭和, 近藤 明, 井上義雄, 山口克人

\section{2 従来手法の分類}

Table1 に，これまで提案されている観測值と基礎方程式 から流れ場を推定する手法をまとめた.

Table 1 Classification of conventional methods

\begin{tabular}{|c|c|c|c|}
\hline 番号 & \multicolumn{2}{|c|}{ 従来の流れ場の推定手法 } & 参考文献 \\
\hline (1) & \multirow[t]{3}{*}{$\begin{array}{l}\text { 漂度観測值を } \\
\text { 用いる方法 }\end{array}$} & $\begin{array}{l}\text { 漂度のみを用いる方法 } \\
\text { (時空間微分法) }\end{array}$ & 文献 1) \\
\hline (2) & & 連続式と融合させる方法 & 文献 2) \\
\hline (3) & & $\begin{array}{l}\text { 連続式, 運動方程式ट } \\
\text { 融合させる方法 }\end{array}$ & 文献 3) \\
\hline (4) & \multicolumn{2}{|c|}{ 温度観測值を用いる方法 } & 文献 4) \\
\hline (5) & \multirow{2}{*}{\multicolumn{2}{|c|}{$\begin{array}{l}\text { 圧力観測值を用いる方法 } \\
\text { スカラー・速度観測值をそれぞれ単独で } \\
\text { 用いる方法 (4 次元同化法) }\end{array}$}} & 文献 5) \\
\hline (6) & & & 文献 6) \\
\hline (7) & \multirow[t]{2}{*}{$\begin{array}{l}\text { 速度観測値のみ } \\
\text { を用いる方法 }\end{array}$} & 連続式と融合させる方法 & $\begin{array}{l}\text { 文献 7) } \\
\text { 文献 8) } \\
\text { 文献 9) }\end{array}$ \\
\hline (8) & & $\begin{array}{l}\text { 連続式, 運動方程式と } \\
\text { 融させるる方方法 }\end{array}$ & $\begin{array}{l}\text { 文献 10) } \\
\text { 文献 11) }\end{array}$ \\
\hline
\end{tabular}

次に, 以上の各手法で流れ場を推定する際に考虑されてい る基礎方程式および従属变数を, 相当する費用関数の微分項 $\partial f_{k} / \partial \eta_{j}$ にあてはめてマトリクス表示すると Fig.1のように なる.この図において, $k$ は式 (1) で示した基礎方程式の種 類を, $j$ は推定すべき従属変数の種類を示しており, ○印を 付けた組合せの $\partial f_{k} / \partial \eta_{j}$ が考虑されていることを, すなわ ち基礎方程式 $f_{k}$ に含まれる従属変数の持つ情報が, 基礎方 程式 $f_{k}$ を通じて $\eta_{j}$ の推定に用いられていることを示して いる. なお提案されている手法の多くは, 実際には費用関数 法の考え方を用いておらず, 式 (2),(3) において $\eta_{j}=\eta_{j, o b s}$ としているものが多い.

\section{3. 一般化費用関数法}

\section{1 一般化費用関数法の構成}

一般化費用関数法 (GCFM) は, 観測によって得られる速 度, 温度, 濃度などの各情報はそれ自身の場全体を推定する 手掛かりであると同時に, 他の状態量を推定する手掛かりに もなり得るとの観点に立ち, 関連する $f_{k}, \eta_{j}-\eta_{j, o b s}$ を全て 用いて費用関数を定義し, $\partial f_{k} / \partial \eta_{j} \neq 0$ 亡なる微分項は全て 考虑してこれを最小化することにより, より合理的な流れ場 を得ようとする方法である. GCFM の一般化式および最適 化手法は式 (2),(3) に示した通りであるが，さらに費用関数 を構成する次元の異なる各項を同等に評価するための等価係 数, および等価係数により同等に評価される各項の寄与を目 的に応じて主観的に操作するための重み係数を導入すると, 式 (2) は次のように書き換えられる.

$$
\begin{aligned}
C F= & \int\left[\sum_{k}\left\{\alpha_{k} \beta_{k} f_{k}^{2}\left(\xi_{i}, \eta_{j}\right)\right\}\right. \\
& \left.+\sum_{j}\left\{\alpha_{j} \beta_{j}\left(\eta_{j}-\eta_{j, o b s}\right)^{2}\right\}\right] d \xi
\end{aligned}
$$

ただし， $\alpha_{k}, \alpha_{j}$ : 重み係数, $\beta_{k}, \beta_{j}$ : 等価係数

なお等価係数としては, 各従属変数が同程度の不確かさで 解とは異なる值をもったとき, 費用関数各項に等価係数を乗 じたものの変化量が等しくなることが必要である. しかし,

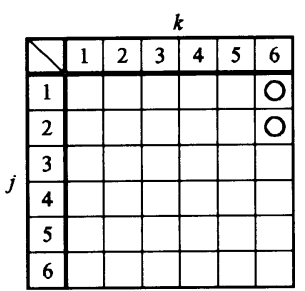

従来手法(1)

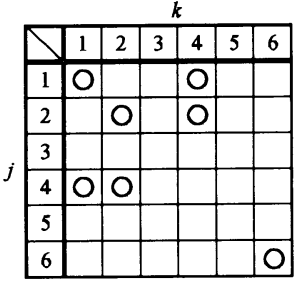

従来手法(3)

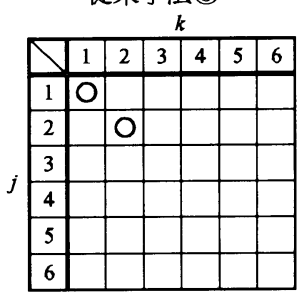

従来手法(5)

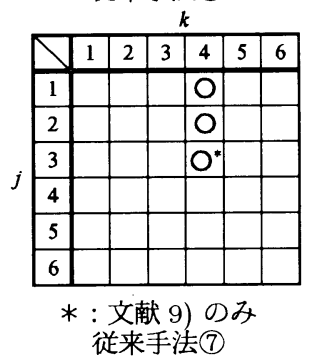

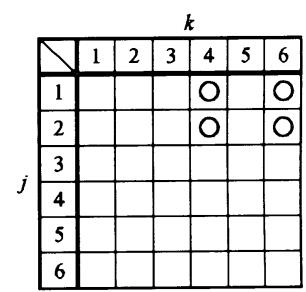

従来手法(2)

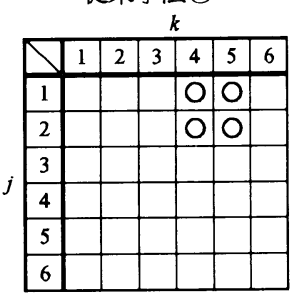

従来手法(4)

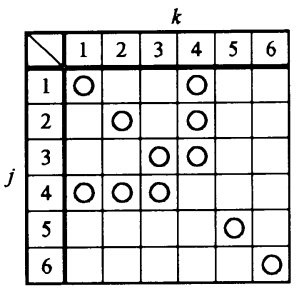

従来手法(6)

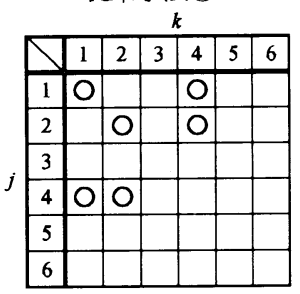

従来手法8
Fig.1 Matrix relations of conventional methods

一般に解は未知であるので, その代替として数値解析結果を 用い, 各計算点の值を測定機器や測定手法により発生し得る と想定される最大誤差の範囲でランダムに変化させ, そのと きの費用関数各項の変化量が等しくなるように等価係数を決 定する.

\section{2 従来手法との関係}

従来手法のうち, 速度場の他に温度場と濃度場を考慮する 4 次元同化法 (FDDA) および GCFM で用いる $\partial f_{k} / \partial \eta_{j}$ を, 二次元定常非等温の空間において污染物質の濃度分布か存在 する場合を例にマトリクス表示すると, Fig.2 のようになる.

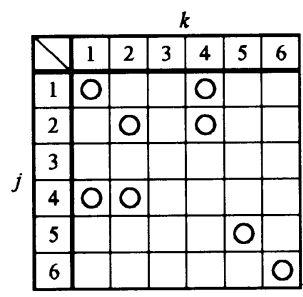

FDDA

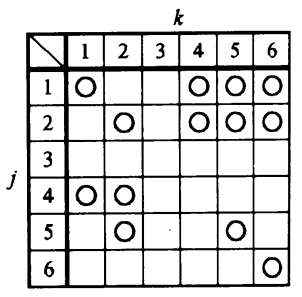

GCFM
Fig.2 Matrix relations of FDDA and GCFM

なお, 二次元空間での浮力項は $j=2$ の方に現れると し, 温度場の流れ場への影響は Boussinesq 近似できるとし ている. また物質輸送はパッシブであるとしている. 
このように，2章で分類した流れ場推定のための各種の 方法は全て, 式 (4) の費用関数の $f_{k}^{2}$ の一部を無視するか, $\eta_{j}=\eta_{j, o b s}$ とするか, あるいは $\partial f_{k} / \partial \eta_{j}$ の一部を 0 とおく ことに相当する手法となっており, 原理的に GCFM の一簡 略化手法として位置付けられることが確認できる.

\section{4. 数値実験による比較計算}

\section{1 対象流れ場}

対象流れ場として, Fig.3に示すような室内に熱源と污染 源 (○印) が存在する二次元定常非等温場を想定した. ここ て室寸法は $W 4,000^{\mathrm{mm}} \times H 2,200^{\mathrm{mm}}$, 給気口および排気口 の寸法は共に $425^{\mathrm{mm}}$ とした.

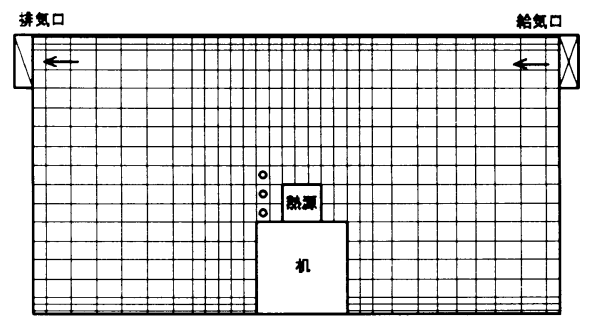

Fig.3 Object room and grid pattern

この流れ場に対して 2 通りの数值計算を行った. 1 つは 観測時の境界条件が正確には把握できていない場合を想定 し, 費用関数による最適化計算のために仮定した境界条件で 計算を行ったもので,これは初期値の観測值欠測部の補間に 用いる. もう 1 つは正解值用として, 流入速度, 発熱分布, 污染物発生分布の境界条件を若干変更して数値計算を行った もので，これに観測に伴う久測箅所を設定してその一部を間 引いたものを観測値とした.この 2 通りのデータを用いて， GCFM の有効性を検証するための比較を行った.

\section{2 数值計算}

Table2 に融合・初期値計算，および正解值・観測値計算 に用いた境界条件を示す.なおこのときのレイノルズ数は, 融合・初期值計算の条件で約 22,900 , 正解值・観測值計算の 条件で約 28,600 であり, 両者の計算とも乱流モテルに標準 $k-\varepsilon$ モデル, 压力解法に SIMPLE 法, 差分にべき乗則を 用いた。

融合・初期値計算の境界条件での数値計算により得られた 速度分布および下流側の温度，濃度分布を Fig.4 に示す．な お, 以下の計算結果は全て無次元表示とする.

Table 2 Boundary conditions

\begin{tabular}{|c|c|c|}
\hline & 融合・初期值計算 & 正解値・観測值計算 \\
\hline 流入条件 & 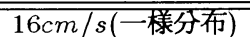 & $20 \mathrm{~cm} / \mathrm{s}$ (一様分布 $)$ \\
\hline 流出条件 & \multicolumn{2}{|c|}{ 自由解放 } \\
\hline \multirow{2}{*}{ 発熱条件 } & \multicolumn{2}{|c|}{$200 \mathrm{~W}$} \\
\hline & (各面から一様) & (上面が側面の 4 倍) \\
\hline 濃度条件 & 3 メッシ & $\begin{array}{l}\text { 下から 1:2:3 の比率 } \\
\text { (棇発生量は左に同じ) }\end{array}$ \\
\hline 壁面条件 & 発熱面および官 & 万部以外は断熱壁 \\
\hline
\end{tabular}

また, Table2 の正解值・観測値の境界条件での数値計算 により得られた速度分布および下流側の温度, 濃度分布を Fig.5 に示す.
Fig.5 では, 流入速度を Fig.4 の場合より 25\%大きくした 結果, 給気側の循環が逆方向になっており, 温度, 濃度分布 とも高い值が下流側に集中している.

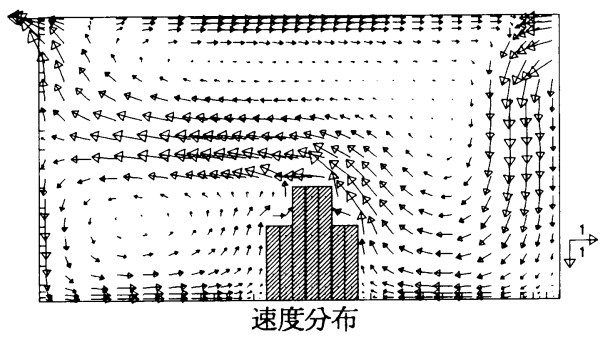

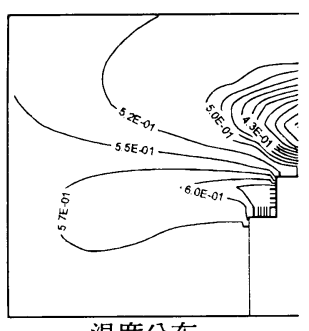

温度分布

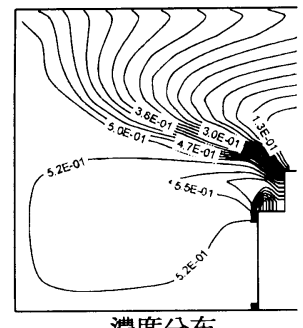

濃度分布
Fig.4 CFD result with boundary condtion of combine

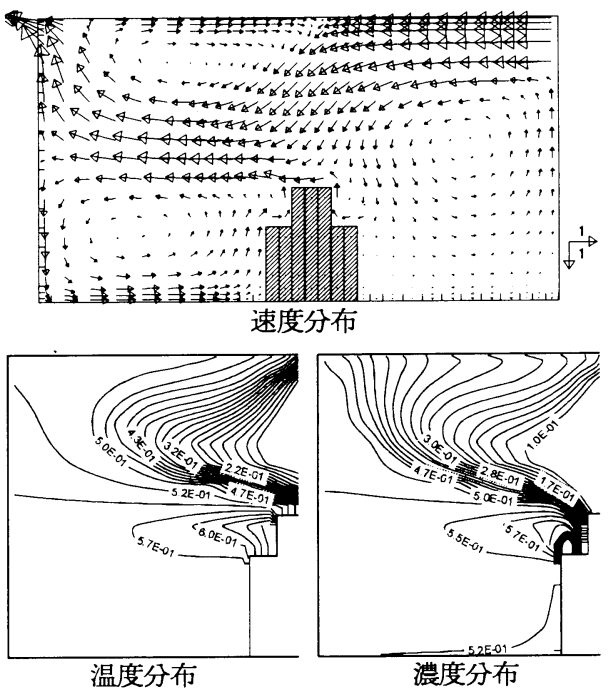

Fig.5 CFD result with boundary condition of observation

次に, Fig.5 の正解值に対して, Fig.8 のように領域を分 け, 初期値との差が明確に現れている領域を重点的に観測す ることを想定して, (1)の領域は速度をランダムに $1 / 2$ に間引 いたもののみを, (2)の領域は温度のみを間引がに, (3)領 域は濃度のみを間引かずに与えたものを観測値とした.

\section{3 融合計算}

前節で得た観測值の欠測部を Fig.4 の数值計算值で補間し て初期値とし, 従来手法のうち, スカラー, 速度観測值を用 いる 4 次元同化法と等価な手法として, まず, Fig.2 左図に 示す $f_{k}, \eta_{j}$ の組合せを用いて推定した速度分布および下流側 の温度, 濃度分布を Fig.6 に示す.

次に, GCFM として Fig.2 右図に示す $f_{k}, \eta_{j}$ の組合せを 用いて推定した速度分布および下流側の温度, 濃度分布を Fig.7 に示す. なお等価係数は, 速度, 温度, 濃度の観測値 がともに最大 $\pm 10 \%$ の誤差を持つとして算出し, 費用関数 の各項への重み係数は全て 1.0 とした. 

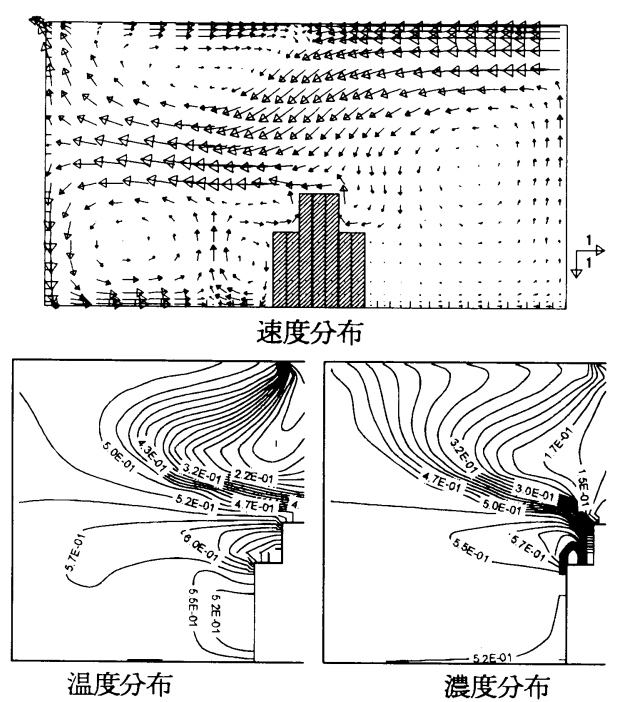

Fig.6 Combine result with conventional method
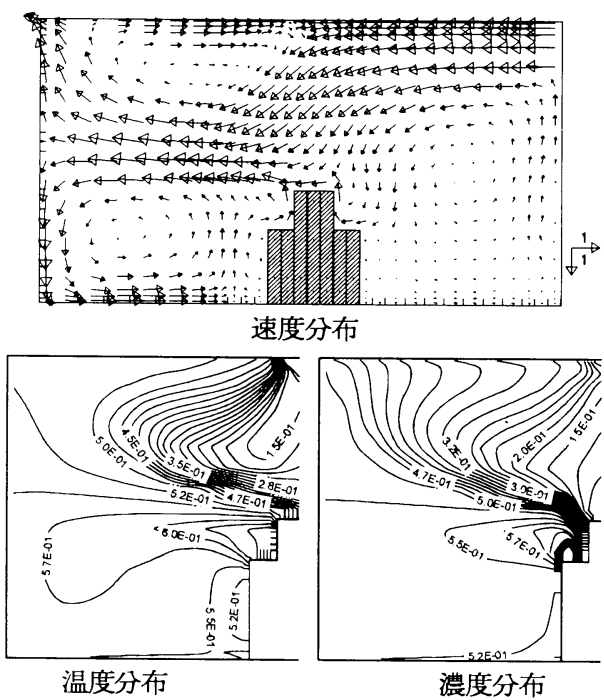

Fig.7 Combine result with GCFM

\section{5. 結果と考察}

以上の結果について, 速度, 温度, 濃度の正解值との誤差 を推定值と正解值の差の RMS で評価したものを, Table3 に 示す. なお式中の值には無次元量を用いているので, 得られ た誤差は各従属変数の代表值に対する比率と見なすことがで きる. 結果を見ると, 速度, 温度, 濃度ともに GCFM の方 が正解值により近く復元できていることが分かる.

Table 3 Comparison of error

\begin{tabular}{c|c|c|c}
\hline & 速度 & 温度 & 濃度 \\
\hline \hline 初期值計算 & $64.0 \%$ & $20.3 \%$ & $10.7 \%$ \\
\hline 従来の費用関数法 & $20.5 \%$ & $10.2 \%$ & $6.71 \%$ \\
\hline GCFM & $16.6 \%$ & $9.92 \%$ & $6.34 \%$ \\
\hline
\end{tabular}

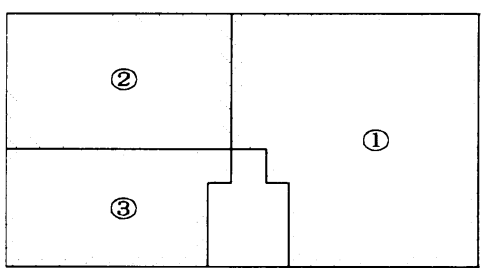

Fig.8 Instituted domain

以上から，本報で提案した GCFM は，観測値の持つ情報 を活かして，より正確な流れ場の推定を可能にすることが分 かった. 特に今回の数值実験で対象とした流れ場のように, 観測值の種類により観測点に偏りがあり，それらの補間が困 難な場合に特に有効であると推察できる.

\section{参考 文 献}

1）例えば奥野，西尾，杉井 : 画像の時空間微分を用いた流場 の計測手法とその応用, 可視化情報, 17-Suppl.1(1997). pp.133-136

2) 須崎, 木村, 加賀, 黒江 : ニューラルネットワーク を用いた勾配法に基づく PIV 計測，可視化情報，19Suppl.2(1999), pp.163-166

3）杉井, 奥野, 西尾: 流場モデを用いた速度場の画像計 測 (第 3 報), 可視化情報, 17-Suppl.2(1997), pp.177-180

4) 桃瀬, 浅見, 竹重, 細川：熱対流場の温度分布を用い た流れ場の推定, 空気調和・衛生工学論文集, 48(1992). pp.89-95

5) 北條，柏原：PIV における圧力情報を用いた速度べク トルの補間法, 可視化情報, 20-77(2000), pp.139-144

6) 例えば鵜野：4 次元データ同化手法による関東地域の 局地循環シミュレーションと評価, 大気環境学会誌, 306(1995), pp.351-366

7) 木村, 服部, 黒江, 加賀 : ニューラルネットワークに よる流れ場の速度分布推定, 計測自動制御学会論文集, 34-12(1998), pp.1800-1805

8) 村井, 井戸, 石川, 山本 : CFD の手法を用いたPIV 計 測結果のポストプロセッシング法の開発, 日本機械学会 論文集 B 編, 64-626(1998), pp.3249-3256

9) 高木, 岡本 : 疎な流速べクトルからのファジィ推論に よる 3 次元流速分布再構築, 可視化情報, 20-77(2000), pp.165-171

10) 登里, 小河原, 飯田 : 移動最小二乗法による CFD-PIV ハイブリッドシステムの開発, 機械学会全国大会講演論 文集, (1998), pp.191-192

11）山口, 加賀, 近藤, 井上, 山口, 塩田 : 費用関数を用い た最適化手法によるPIV とCFD の融合, 日本機械学会 論文集 B 編, 66-642(2000), pp.339-345 